\title{
Impact of irrigation protocols with some chelators and mechanical agitation on intratubular decontamination
}

\author{
Victor Feliz PEDRINHA ${ }^{(a)}$ \\ Maricel Rosario CARDENAS \\ CUELLAR(b) \\ Evelyn Giuliana \\ Velásquez-ESPEDILLA(b) iD \\ Marco Antonio Hungaro \\ DUARTE(b) $^{(b)}$ \\ Flaviana Bombarda de \\ ANDRADE(b) \\ Patrícia de Almeida \\ RODRIGUES(a) ic \\ (a) Universidade Federal do Pará - UFPA, \\ Graduate Program in Dentistry, Laboratory \\ of Dental Materials, Belém, PA, Brazil. \\ (b) Universidade de São Paulo - USP, Bauru \\ Dental School, Department of Operative \\ Dentistry, Dental Materials and Endodontics, \\ Bauru, SP, Brazil.
}

Declaration of Interests: The authors certify that they have no commercial or associative interest that represents a conflict of interest in connection with the manuscript.

Corresponding Author:

Victor Feliz Pedrinha

E-mail: victor_feliz18@hotmail.com

ht1ps://doi.org/10.1590/1807-3107bor-2021.vol35.0127

Submitted: August 13, 2020

Accepted for publication: May 5, 2021

Last revision: June 10, 2021

\begin{abstract}
This study evaluated main canal and intratubular decontamination using different irrigation solutions followed by adjunctive agitation steps for infected root canals. Sixty-eight lower incisors were contaminated with Enterococcus faecalis and allocated to groups according to canal treatment $(\mathrm{n}=10)$ : $\mathrm{G} 1, \mathrm{NaOCl}$ followed by ethylenediaminetetraacetic acid (EDTA); G2, a mixture of $\mathrm{NaOCl}$ with hydroxyethylidene bisphosphonate (HEBP); and $\mathrm{G} 3, \mathrm{NaOCl}$ followed by EDTA-T (EDTA with sodium lauryl ether sulfate). All three groups of teeth were agitated with passive ultrasonic irrigation (PUI) using saline solution, whereby G4, G5, and G6 were prepared as above, and agitation was performed using an XP-Endo Finisher instrument. Microbiological samples were collected from the root canals with paper points at three times: before and after chemomechanical preparation and after agitation. The colony-forming units (CFU)/ $\mathrm{mL}$ count was determined, and bacterial intratubular viability was analyzed via confocal laser scanning microscopy using Live/Dead staining. Statistical analysis was performed using a Kruskal-Wallis test followed by Dunn tests. A Friedman test was applied for colony-counting data $(\alpha=0.05)$. $\mathrm{CFU} / \mathrm{mL}$ counting indicated equally effective decontamination in the experimental groups ( $p>0.05$ ). According to microscopy images, the use of irrigation solutions followed by agitation with the XP-Endo Finisher yielded better results. Moreover, $\mathrm{NaOCl+EDTA-T}$ followed by $X P$-Endo Finisher resulted in significantly lower viability than in the PUI-activated groups $(\mathrm{p}<0.05)$. The cervical and medium thirds of the specimens presented similar results. Overall, $\mathrm{NaOCl}+\mathrm{EDTA}-\mathrm{T}$ exhibited the best intratubular antibacterial activity, mainly for canals that were subsequently agitated using XP-Endo Finisher.
\end{abstract}

Keywords: Root Canal Irrigants; Microscopy, Confocal; Enterococcus faecalis; Endodontics; Root Canal Therapy.

\section{Introduction}

Chemomechanical procedures are important for achieving efficient cleaning, canal shaping, debridement, and consequently reducing bacteria to levels that are compatible with periradicular tissue healing. ${ }^{1}$ For this purpose, chemical substances are used with the mechanical action of instruments during the preparation of root canals. Sodium hypochlorite 
$(\mathrm{NaOCl})$ and ethylenediaminetetraacetic acid (EDTA) are the most frequently used chemical solutions to date. Indeed, due to its organic dissolution and antimicrobial properties, $\mathrm{NaOCl}$ has the highest disinfectant potential in endodontics, and EDTA is applied as a chelating agent. ${ }^{2}$ Other solutions can be used in clinical practice, such as sodium lauryl ether sulfate, an anionic surfactant used to improve the action of EDTA, as well as EDTA-T (EDTA plus sodium lauryl ether sulfate), which has reduced surface tension and greater antiseptic activity. ${ }^{3}$ Combinations of chelators, such as hydroxyethylidene bisphosphonate, better known as etidronate (HEBP), with $\mathrm{NaOCl}$ have also been evaluated. The use of HEBP has been proposed because it is a weak and biocompatible chelating agent that reduces debris accumulation and removes inorganic components from the smear layer while preserving the properties of $\mathrm{NaOCl}^{4,5}$

Nevertheless, despite instrumentation for root canals, the action of instruments and irrigation solutions does not provide complete cleaning and disinfection because unprepared surfaces of canals may contain microorganisms. ${ }^{1}$ Furthermore, the capacity of microorganisms to form biofilms ensures their resistance to chemical and mechanical stresses, complicating their removal. ${ }^{6}$ When microorganisms cannot be removed, they must be killed because not only bacteria but also bacterial components can induce apical pathosis. ${ }^{7}$ Thus, strategies to improve irrigation and shaping performance should be encouraged. ${ }^{1}$ In this context, physical adjunctive procedures, such as ultrasonic and mechanical agitation, have been proposed to supplement the effects of chemomechanical instrumentation. ${ }^{8} \mathrm{~A}$ commonly used method is passive ultrasonic irrigation (PUI). Although this approach is recommended to agitate the irrigation solution, inducing cavitation and acoustic streaming, ${ }^{8-10}$ studies have shown conflicting results with regard to the cleaning and disinfecting effects of PUI. ${ }^{11-15}$

Another strategy is the use of the XP-Endo Finisher instrument (FKG Dentaire, La Chaux-de-Fonds, Switzerland), which was introduced to complement the cleaning of root canals after chemomechanical preparation. This rotary instrument is manufactured with a heat-treated nickel-titanium alloy (NiTi)
(MaxWire; Martensite-Austenite Electropolish Flex, FKG Dentaire), which allows it to change shape according to temperature. At room temperature, in its martensitic phase (phase $\mathrm{M}$ ), the instrument remains straight. However, when subjected to intracanal temperatures, the instrument enters its austenitic phase (phase A) and takes the shape of a 1.5-mm-deep spoon in the final $10 \mathrm{~mm}$ of its length. In theory, the instrument adopts the A-phase shape when in rotation inside the canal, and its expansion and contraction enable the irrigant to touch the canal walls, including areas that other instruments do not reach. ${ }^{12,16,17}$ Studies have shown promising results regarding the removal of debris, root canal filling, and calcium hydroxide from canals. ${ }^{15,18,19}$ In a recent investigation, the XP-Endo Finisher instrument exhibited better performance than PUI in distributing an irrigant throughout the root canal system ${ }^{9}$, and another analysis showed favorable results for the ability of the XP-Endo Finisher instrument to remove both biofilm and bacteria from root canals. ${ }^{12,17,18}$

In general, the cleaning and disinfection actions of PUI and the XP-Endo Finisher instrument should be carefully considered when researchers perform adjunctive steps with antimicrobial agents, such as $\mathrm{NaOCl},{ }^{12,17}$ which is the strategy used in clinical practice. However, under in vitro conditions, this procedure can result in a low bacterial level for comparison. Physical-mechanical action is necessary for greater effectiveness of irrigation solutions, ${ }^{20}$ and a microbiological investigation of the physical-mechanical effects of adjunctive devices in root canals with previous chemomechanical preparation is necessary to establish which method provides better disinfection activity regarding mechanical effects.

Accordingly, the main aim of this study was to evaluate bacterial reduction in root canals of lower incisors contaminated with Enterococcus faecalis (E. faecalis) after chemomechanical preparation with different irrigant solutions followed by the physical-mechanical action of adjunctive agitation steps, namely, PUI or the XP-Endo Finisher instrument. The null hypothesis tested was that no differences in antimicrobial efficacy exists between the irrigating solutions and agitation steps employed. 


\section{Methodology}

\section{Solutions}

The substances used in the present study were saline $(0.9 \%$ sodium chloride, $\mathrm{NaCl}), \mathrm{NaOCl}$, EDTA, HEBP, and EDTA-T solutions. The saline, EDTA, and EDTA-T (Formula e Ação, São Paulo, SP, Brazil) solutions were purchased from commercially available sources. The other solutions were prepared according to methodologies previously described in the literature. ${ }^{4,5}$ A stock solution of $\mathrm{NaOCl}$ (Sigma-Aldrich, St. Louis, MO, USA) was titrated iodometrically to determine the available chlorine content. Next, the solution was diluted to $2.5 \%$ and $5 \% \mathrm{NaOCl}$ using distilled water. The pure chemical product was mixed with distilled water to obtain an 18\% HEBP solution (Zschimmer \& Schwarz Mohsdorf GmbH \& Co. KG, Burgstadt, Germany). Concentrations of $5 \%$ and $18 \%$ were used to prepare a 1:1 mixture of $\mathrm{NaOCl}$ and $\mathrm{HEBP}$, respectively, before experiments. All solutions were prepared, used immediately after mixing, and stored in dark containers at $5^{\circ} \mathrm{C}$ between experiments. Before use, all solutions were removed from refrigeration and stored at room temperature for $60 \mathrm{~min}$.

\section{Preparation of specimens}

This study was approved by the Ethics and Research Committee of the local university (number: 2.492.804). A power calculation was performed using G*Power 3.1 software (Heinrich Heine University, Dusseldorf, Germany), as performed based on a previous study with the same intratubular contamination methodology. ${ }^{21}$ Teeth were collected from adult patients between 20 and 35 years old. Sixty-eight human lower incisors recently extracted due to periodontal diseases were used. Periapical radiographs were acquired in the mesiodistal and buccolingual directions to select teeth with a single canal and similar radiographic root canal morphology. Teeth with small volumes and thin root canals, suggesting calcification or tubular sclerosis, were discarded. The teeth were stored in saline at $4^{\circ} \mathrm{C}$ until use. Organic debris was removed from the root surface using Gracey periodontal curettes (SSWhite, Duflex, Rio de Janeiro, Brazil), after which the crowns were sectioned horizontally at the cementoenamel junction using diamond disks (KG Sorensen, São Paulo, Brazil) under abundant irrigation. The root specimen length was standardized at $12 \mathrm{~mm} \pm 1 \mathrm{~mm}$. The specimens were randomly distributed to all experimental groups.

The canals were explored with K\#10 files (Dentsply Maillefer, Ballaigues, Switzerland) until the tip of the instrument was juxtaposed to the apical foramen. The working length $(\mathrm{WL})$ was defined as the measurement minus $1 \mathrm{~mm}$. To standardize the initial diameter of the canals, they were widened with the X1 instrument of the ProTaper Next system (PTN, Dentsply Maillefer, Ballaigues, Switzerland), opening up space for microorganism inoculation. Irrigation was performed with $5 \mathrm{~mL}$ of saline solution; this was followed by $5 \mathrm{~mL}$ of $17 \%$ EDTA for three minutes and then $5 \mathrm{~mL}$ of saline solution using NaviTip needles (Ultradent Products Inc., South Jordan, UT, USA) taken up to $3 \mathrm{~mm}$ short of the WL. The specimens were subjected to three successive ultrasonic baths for $10 \mathrm{~min}$ each in $1 \% \mathrm{NaOCl}, 17 \%$ EDTA, and phosphate-buffered saline (PBS) solution followed by distilled water to eliminate EDTA and sodium hypochlorite residues and open up the dentinal tubules according to a previously described protocol. ${ }^{10,22}$

The outer surfaces of all roots were coated with a double layer of red nail polish (Colorama, Rio de Janeiro, Brazil) such that intratubular bacterial penetration could occur only through the main root canal. After drying (24 h), the specimens were individually placed in microtubes (Axygen, Union City, USA) containing $1.5 \mathrm{~mL}$ of distilled water and sterilized in an autoclave (Sercon, Model HG, Mogi das Cruzes, Brazil) at $121^{\circ} \mathrm{C}$ for $20 \mathrm{~min}$.

\section{Intratubular contamination}

The bacterial reference strain of E. faecalis (ATCC 29212) was acquired, and colony morphology and Gram staining were assessed several times throughout the experiment to confirm purity. The microorganisms were cultivated in brain heart infusion (BHI) broth with successive subcultures. Dilutions were performed based on the absorbance value obtained with an SF325NM spectrophotometer (Bel Photonics do Brazil Ltda, Osasco, Brazil) to a concentration of $3 \times 10^{8}$ colony-forming units $(\mathrm{CFU}) / \mathrm{mL}$. The tooth 
specimens were contaminated over a 5-day period in $\mathrm{BHI}$ medium at $37^{\circ} \mathrm{C}$ following the Ma et a ${ }^{23}$ sequence of centrifugation steps ${ }^{23}$ and the Andrade et al. ${ }^{21}$ protocol ${ }^{21}$, which has been described previously. ${ }^{10,24,25}$ Eight specimens were randomly selected as positive controls $\left(\mathrm{C}^{+}\right)$to confirm intratubular contamination; two additional specimens were selected as negative controls (C) to confirm sterility.

\section{Instrumentation procedures}

All experiments were performed under aseptic conditions inside a laminar flow hood. Mechanical preparation of the canals was performed by a single operator using the XP-Endo Shaper instrument (FKG Dentaire, La Chaux-de-Fonds, Switzerland) activated in a VDW Silver electric motor (VDW GmbH, Munich, Germany) at $800 \mathrm{rpm}$ and $1.0 \mathrm{~N} \cdot \mathrm{cm}$ and inserted in the canals with vertical movements until the WL was reached. To simulate the intracanal temperature and promote a phase change of the instrument, all irrigation solutions used were preheated $\left(36 \pm 1^{\circ} \mathrm{C}\right)$ in a thermometer-controlled ultrasonic cleaner (Gnatus, Barretos, Brazil). Each instrument was used for the preparation of up to four canals according to the manufacturer's recommendations. After root preparation of each specimen, the instrument was removed from the canal and sterilized for another use.

The specimens were distributed into six groups according to the irrigation regimen performed, and the agitation protocol used ( $\mathrm{n}=10)$ was as follows: $\mathrm{G} 1$, $2.5 \% \mathrm{NaOCl}(5 \mathrm{~min}$ ) followed by 17\% EDTA ( $3 \mathrm{~min}$ ); G2, a mixture of $5 \% \mathrm{NaOCl}+18 \%$ HEBP in equal proportions ( $5 \mathrm{~min}$ ) followed by saline solution $(3 \mathrm{~min})$; and $\mathrm{G} 3,2.5 \% \mathrm{NaOCl}(5 \mathrm{~min})$ followed by EDTA-T (3 min). For all groups, a final agitation protocol was performed with PUI and saline solution after final instrumentation. For G4, G5, and G6, the same solution regimens applied in the above groups were used, but the final agitation protocol was performed with the XP-Endo Finisher instrument and saline solution.

First, the canals were irrigated with $5 \mathrm{~mL}$ of irrigation solution plus an additional $5 \mathrm{~mL}$ after instrumentation for a total volume of $10 \mathrm{~mL}$ of $\mathrm{NaOCl}$ or NaOCl/HEBP at a flow rate of $0.167 \mathrm{~mL} / \mathrm{s}(5 \mathrm{~mL}$ for $30 \mathrm{~s}$ ) at each moment. For specimens treated with EDTA or EDTA-T, $5 \mathrm{~mL}$ of these solutions was used for three minutes. For specimens treated with $\mathrm{NaOCl} / \mathrm{HEBP}, 5 \mathrm{~mL}$ of saline solution was used for three minutes. Thus, the volume of irrigant solution used was standardized in all groups. The root canals were irrigated using 30-gauge NaviTip needles taken up to $3 \mathrm{~mm}$ short of the WL by inward and outward movements of $5 \mathrm{~mm}$ in amplitude. $\mathrm{NaOCl}$ was removed from the root canals by aspiration before each application of a chelating agent (EDTA or EDTA-T). The $5 \% \mathrm{NaOCl} / 18 \%$ HEBP mixture was also removed by aspiration. The solutions were inactivated with sterile $5 \%$ sodium thiosulfate before sampling of the main root canal.

To perform each of the agitation protocols with PUI or the XP-Endo Finisher, another $15 \mathrm{~mL}(5 \mathrm{~mL}$ for each agitation) of preheated saline solution $\left(36^{\circ} \mathrm{C}\right)$ was used at a flow rate of $0.167 \mathrm{~mL} / \mathrm{s}$ for $30 \mathrm{~s}$. For PUI in G1, G2, and G3, a piezoelectric device was employed at a frequency of 30,000 Hz (Emisonic MMO Jardim São Carlos, São Carlos, Brazil) with an Irrisonic E1 tip (Helse, Santa Rosa de Viterbo, Brazil) inserted $2 \mathrm{~mm}$ short of the WL for $1 \mathrm{~min}$. The procedure was performed with vertical movements in the buccolingual and mesiodistal directions for three periods of $20 \mathrm{~s}$ each in "endo mode" (10\% power), as previously reported..$^{10}$ For the agitation protocol with the XP-Endo Finisher instruments in G4, G5, and G6, the instrument was mounted on a VDW Silver electric motor at $800 \mathrm{rpm}$ and $1.0 \mathrm{~N} \cdot \mathrm{cm}$ and then inserted into a canal with vertical movements in the buccolingual and mesiodistal directions up to the WL for three periods of $20 \mathrm{~s}^{\text {each. }}{ }^{17}$

\section{Microbiological samples}

Microbiological samples were obtained using two absorbent paper points at three times: before and after instrumentation and after the agitation protocol with PUI or XP-Endo Finisher. All samples were collected with $20 \mu \mathrm{L}$ of sterile saline solution inside the canals to standardize the volume absorbed by the paper. Absorbent paper point \#20 (Dentsply Maillefer, Ballaigues, Switzerland) was inserted into the canals for $1 \mathrm{~min}$ each and then transferred to microtubes containing $1 \mathrm{~mL}$ of $\mathrm{BHI}$ broth according to previous studies. ${ }^{10,26}$ The microtubes were vortexed for $10 \mathrm{~s}$, and $100 \mu \mathrm{L}$ of the content was transferred 
by dilution to other microtubes with $900 \mu \mathrm{L}$ of $\mathrm{BHI}$ until a concentration of $10^{-3}$ was reached. Next, $100-\mu \mathrm{L}$ aliquots of the dilutions were plated on Petri dishes with $\mathrm{BHI}$ agar, which were stored in a bacteriological incubator at $37^{\circ} \mathrm{C}$ for $48 \mathrm{~h}$ for subsequent CFU/ $\mathrm{mL}$ counts. The first samples collected from each specimen before instrumentation were used as positive controls to confirm standardization of the initial contamination level.

\section{Preparation for confocal laser scanning microscopy (CLSM) analysis}

After canal treatment protocols, the specimens were washed with PBS to remove residual irrigant and sectioned longitudinally using an IsoMet machine (Buehler Ltd, Lake Bluff, IL,USA) with a diamond disk under constant irrigation with sterile saline solution. The smear layer resulting from the cut was removed by immersion in 17\% EDTA for 5 min and washing with saline solution as previously reported..$^{23-25}$

Root halves were stained with $30 \mu \mathrm{L}$ of dye from a LIVE/DEAD® BacLight bacterial viability kit (Invitrogen Molecular Probes, Eugene, OR, USA). This kit contains the green dye SYTO $9 \circledR$, which stains viable bacteria, and the red dye propidium iodide, which stains dead bacteria. After 20 min of contact with the dye, each sample was gently washed with PBS to remove residual dye. The specimens were placed on a glass slide with immersion oil and observed using a Leica TCS-SPE confocal microscope (Leica Microsystems GmbH, Mannheim, Germany) at $40 \mathrm{x}$ magnification. Eight sequential images of the cervical and medium thirds of each specimen were obtained, with four images of each root hemisection: two corresponding to the superficial dentinal area and two corresponding to the deeper dentinal area. This allowed for visibility of all the extensions of dentinal tubules contaminated from the main root canal to the cementum. The apical third of the tooth was not used due to the reduced number of dentinal tubules and variable anatomy, as previously observed. ${ }^{21,24,25,26}$

In total, 80 images were obtained for each group, as well as 48 images for the positive controls $\left(\mathrm{C}^{+}\right)$and 16 for the negative controls $\left(\mathrm{C}^{-}\right)$. The images were obtained at a 1- $\mu \mathrm{m}$ step size deep and a resolution of $1024 \times 1024$ pixels. The images were separated into layers and converted into "tiff" format using Leica Application Suite-Advanced Fluorescence software (LAS AF, Leica, Mannheim, Baden-Württemberg, Germany). The images were then exported and analyzed using Leica LASX Life Science software (Leica Microsystems $\mathrm{GmbH}$, Mannheim, Germany) to quantify viable (green) and nonviable (red) bacteria. The percentage of bacterial viability determined for the eight images (cervical, medium, superficial, and deep) of each specimen was calculated using the following formula:

$$
\text { percent }=\frac{\text { volume of green }\left[\mu \mathrm{m}^{3}\right]}{\text { volume of red }+ \text { green }\left[\mu \mathrm{m}^{3}\right]} \times 100
$$

\section{Statistical analysis}

Descriptive statistics for the results are expressed as medians and $95 \%$ confidence intervals and minimum and maximum values. Data distribution was assessed using D'Agostino-Pearson and Shapiro-Wilk tests of normality. CFU counts were log-transformed before statistical analysis. The intracanal efficacy against E. faecalis after preparation is expressed as the percentage of reduction; it was calculated for each group as follows: (CFUs preinstrumentation/CFUs postadjunctive step $x$ 100). ${ }^{27}$ Intragroup and intergroup comparisons were then conducted using Friedman and Kruskal-Wallis tests, respectively, followed by Dunn's post hoc test. Bacterial viability based on CLSM data was statistically evaluated using a Kruskal-Wallis test followed by Dunn's post hoc test. GraphPad Prism 8.0 software (GraphPad San Diego, CA, USA) was used for the analysis, and a significance level of $5 \%$ was adopted.

\section{Results}

\section{Microbiological culture evaluation}

When median, minimum, and maximum $\mathrm{CFU} / \mathrm{mL}$ counts were evaluated, no statistically significant differences were found between the studied irrigation regimes $(p>0.05)$. However, a significant difference $(p<0.05)$ was observed when CFU counts were compared with the positive control (first samples), and these differences were observed in analyses after chemomechanical preparation (second samples) and after the adjunctive steps (third samples) (Table 1). According to negative control specimens, no cross-contamination occurred during the experiment. 
All groups demonstrated the same reduction in bacteria inside the main root canals after chemomechanical preparation and the final agitation protocol, without any significant differences according to CFU counts (Table 1).

\section{CLSM evaluation of intratubular decontamination}

According to CLSM image analysis, there was a higher proportion of viable bacteria inside dentinal tubules in the positive control group (83.7\%, range: 78.6 -91.8), confirming the efficacy of the contamination protocol. All experimental groups showed significantly lower viability values than the positive control group $(p<0.05)$, and no bacterial growth was observed in the negative control group. Comparison between groups showed that in the cervical and medium regions of the roots, such as deep and superficial areas, treatment with irrigation solutions followed by agitation with PUI or the XP-Endo Finisher yielded a similar percentage of viable bacteria $(p>0.05)$. Additionally, no significant differences were found in intragroup comparisons regarding the thirds and depths (Table 2).

Samples subjected to the irrigation regimens followed by agitation with XP-Endo Finisher had lower bacterial viability values than those in the PUI-activated groups. Furthermore, a significant difference was observed between G6 (NaOCl + EDTA-T with final XP-Endo Finisher agitation) and G1, G2, and G3 ( $\mathrm{p}<0.05)$. G6 showed the lowest total viability, at $12.6 \%$ (7.70-19.3), with a superficial viability of $10.9 \%(6.65-19.4)$ and a deep viability of $4.45 \%(4.38-17.0)(p<0.05)$ (Figure).

Table 1. Median (Me), minimum and maximum (Min-Max) CFU/mL and E. faecalis percent reduction (\%) inside root canals for each experimental group.

\begin{tabular}{|c|c|c|c|c|}
\hline \multirow{3}{*}{ Groups $(n=10)$} & Preinstrumentation & Postinstrumentation & Postadjunctive step & Reduction (\%) \\
\hline & (Log 10 CFU/mL) & (Log 10 CFU/mL) & $(\log 10$ CFU/mL) & Me (Min-Max) \\
\hline & Me (Min-Max) & Me (Min-Max) & Me (Min-Max) & \\
\hline \multicolumn{5}{|l|}{ PUI Groups } \\
\hline $\mathrm{NaOCl}+\mathrm{EDTA}$ & $6.15(6.0-6.2)^{\mathrm{Aa}}$ & $3.30(3.3-3.3)^{\mathrm{Bb}}$ & $3.30(3.3-3.3)^{\mathrm{Bb}}$ & $97.15(97.0-97.2)^{*}$ \\
\hline $\mathrm{NaOCl} / \mathrm{HEBP}$ & $6.17(6.0-6.2)^{\mathrm{Aa}}$ & $3.31(3.1-3.6)^{\mathrm{Bb}}$ & $3.30(3.3-3.3)^{\mathrm{Bb}}$ & $97.12(97.1-97.2)^{*}$ \\
\hline $\mathrm{NaOCl}+$ EDTA-T & $6.15(6.0-6.2)^{\mathrm{Aa}}$ & $3.30(3.3-3.4)^{\mathrm{Bb}}$ & $3.30(3.3-3.3)^{\mathrm{Bb}}$ & $97.15(97.0-97.2)^{*}$ \\
\hline \multicolumn{5}{|l|}{ XP-Endo Groups } \\
\hline $\mathrm{NaOCl}+\mathrm{EDTA}$ & $6.18(6.1-6.2)^{\mathrm{Aa}}$ & $3.30(3.3-3.3)^{\mathrm{Bb}}$ & $3.30(3.3-3.3)^{\mathrm{Bb}}$ & $97.12(97.0-97.1)^{*}$ \\
\hline $\mathrm{NaOCl} / \mathrm{HEBP}$ & $6.20(6.0-6.2)^{\mathrm{Aa}}$ & $3.30(3.3-3.3)^{\mathrm{Bb}}$ & $3.30(3.3-3.3)^{\mathrm{Bb}}$ & $97.10(97.0-97.2)^{*}$ \\
\hline $\mathrm{NaOCl}+$ EDTA-T & $6.16(6.1-6.2)^{\mathrm{Aa}}$ & $3.32(3.1-3.3)^{\mathrm{Bb}}$ & $3.30(3.3-3.3)^{\mathrm{Bb}}$ & $97.14(97.0-97.1)^{*}$ \\
\hline
\end{tabular}

Comparison by Kruskal-Wallis and Dunn's post hoc tests $(p<0.05)$. Different uppercase superscripted letters in a column represent significant differences between groups; different lowercase superscripted letters in a row represent significant differences within groups. ${ }^{*}$ No statistically significant difference.

Table 2. Median (95\% confidence interval) percentage of viable bacteria in the dentinal tubules after treatment of each group.

\begin{tabular}{lccccc}
\hline Groups & Total & Cervical & Medium & Superficial & Deep \\
\hline $\begin{array}{l}\text { Control } \\
\text { PUI Groups }\end{array}$ & $83.7(78.6-91.8)^{\mathrm{Aa}}$ & $93.5(89.6-95.5)^{\mathrm{Aa}}$ & $97.4(89.6-96.4)^{\mathrm{Aa}}$ & $83.7(77.6-92.2)^{\mathrm{Aa}}$ & $94.3(67.5-90.1)^{\mathrm{Aa}}$ \\
$\mathrm{NaOCl}+\mathrm{EDTA}$ & $38.7(30.3-46.7)^{\mathrm{Ba}}$ & $40.4(27.6-53.2)^{\mathrm{Ba}}$ & $38.6(24.1-46.5)^{\mathrm{Ba}}$ & $37.9(29.3-43.9)^{\mathrm{Ba}}$ & $32.6(27.2-45.5)^{\mathrm{Ba}}$ \\
$\mathrm{NaOCl} / \mathrm{HEBP}$ & $31.3(28.0-44.0)^{\mathrm{Ba}}$ & $25.0(19.0-41.0)^{\mathrm{Ba}}$ & $40.0(27.2-51.9)^{\mathrm{Ba}}$ & $40.2(25.7-42.3)^{\mathrm{Ba}}$ & $26.9(22.7-37.0)^{\mathrm{Ba}}$ \\
$\mathrm{NaOCl}+$ EDTA-T & $31.1(26.7-42.3)^{\mathrm{Ba}}$ & $28.7(19.2-35.8)^{\mathrm{Ba}}$ & $34.3(23.3-48.5)^{\mathrm{Ba}}$ & $36.8(25.6-46.6)^{\mathrm{Ba}}$ & $32.3(22.9-38.6)^{\mathrm{Ba}}$ \\
$\mathrm{XP}-\mathrm{Endo} \mathrm{Groups}$ & & & & & \\
$\mathrm{NaOCl}+\mathrm{EDTA}$ & $26.1(21.5-31.5)^{\mathrm{BCa}}$ & $22.8(17.4-34.3)^{\mathrm{Ba}}$ & $26.7(19.5-39.2)^{\mathrm{Ba}}$ & $21.5(18.3-33.3)^{\mathrm{BCa}}$ & $29.8(19.4-33.5)^{\mathrm{BCa}}$ \\
$\mathrm{NaOCl} / \mathrm{HEBP}$ & $21.4(14.3-26.2)^{\mathrm{BCa}}$ & $20.0(8.72-29.0)^{\mathrm{Ba}}$ & $23.7(12.8-30.2)^{\mathrm{Ba}}$ & $14.1(12.4-28.6)^{\mathrm{BCa}}$ & $20.4(13.2-29.5)^{\mathrm{BCa}}$ \\
$\mathrm{NaOCl}+$ EDTA-T & $12.6(7.70-19.3)^{\mathrm{Ca}}$ & $13.9(5.21-22.7)^{\mathrm{Ba}}$ & $8.00(1.30-20.5)^{\mathrm{Ba}}$ & $10.9(6.65-19.4)^{\mathrm{Ca}}$ & $4.45(4.38-17.0)^{\mathrm{Ca}}$ \\
\hline
\end{tabular}

Kruskal-Wallis test and Dunn's test $(p<0.05)$. Different uppercase superscripted letters in a column represent significant differences between groups; different lowercase superscripted letters in a row represent significant differences within groups. 


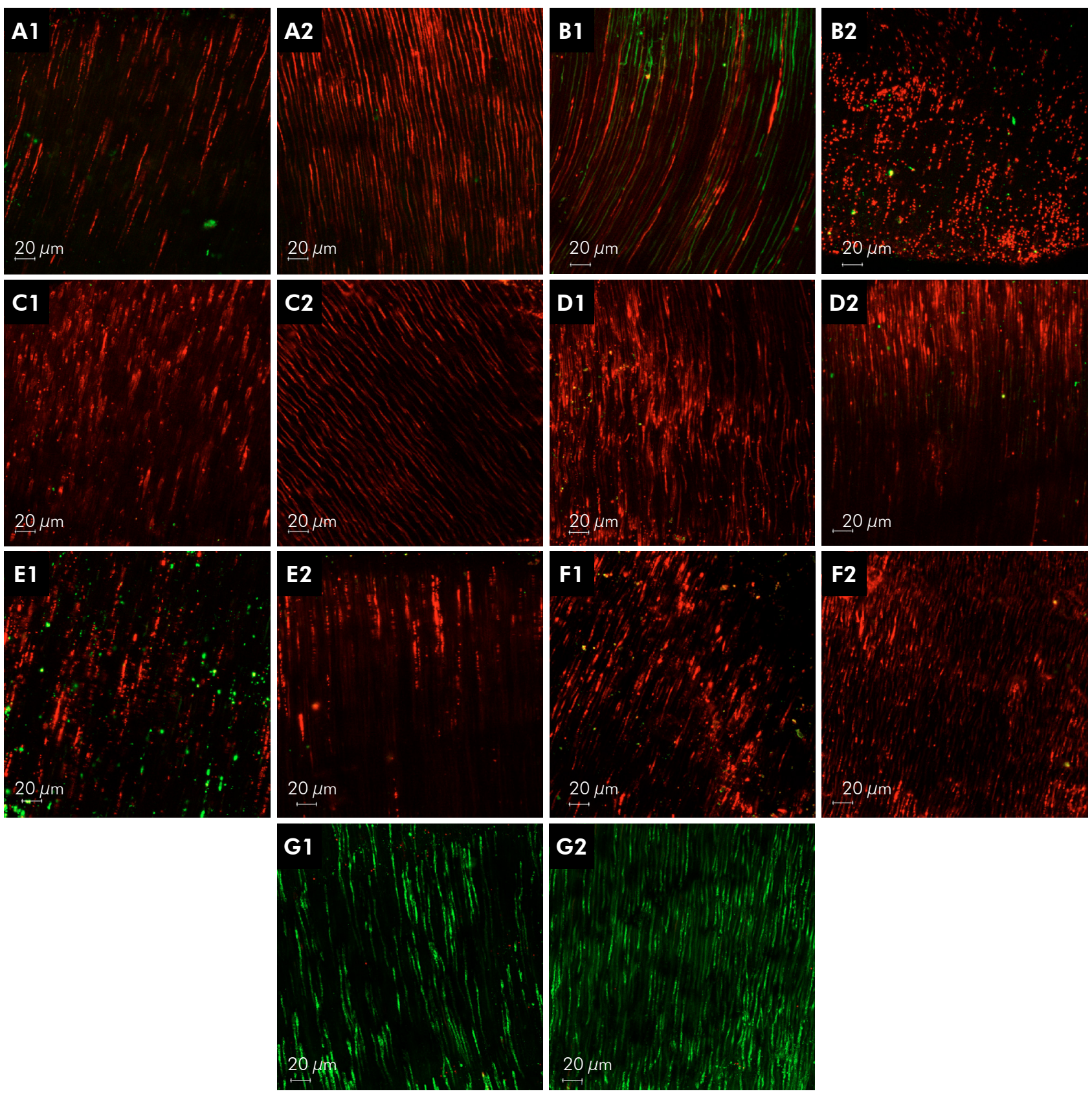

Figure. CLSM images of specimens treated with (A) $\mathrm{NaOCl}+$ EDTA followed by PUI; (B) a mixture of NaOCl/HEBP followed by PUI; and (C) NaOCl + EDTA-T followed by PUI. (D), (E), and (F) were subjected to the same irrigation protocols as the above groups but were treated with the XP-Endo Finisher instrument. (G) Control group. Number 1 corresponds to the cervical third; number 2 is the medium third. Viable bacteria are indicated in green, and nonviable bacteria are indicated in red. Magnification: 40 x. Bars: $20.0 \mu \mathrm{m}$.

\section{Discussion}

In this study, microbiological analysis of canal samples was performed via CFU/mL counting to investigate contamination in the main canal, and intratubular contamination was evaluated with CLSM in the same specimen. Antimicrobial solutions cannot penetrate biofilms without the aid of physical-mechanical action, especially when the biofilms are densely organized. Moreover, the biofilm 
remaining after treatment may reorganize, causing a risk to the resolution of apical periodontitis. ${ }^{28}$ Thus, saline solution was used during adjunctive steps to investigate how only the physical-mechanical action of adjunctive devices could enable disinfection superior to that achieved by chemomechanical preparation.

$E$. faecalis was the bacterial species chosen for this study due to its characteristics of commonly being isolated from persistent infections, capacity for deep intratubular penetration, adherence to dentin collagen, and biofilm formation, which contribute to bacterial resistance to chemomechanical procedures. ${ }^{27}$ Furthermore, these bacteria can achieve a viable but unculturable state by activating a starvation response under stress conditions, which allows regrowth. ${ }^{29}$ Although a single-species biofilm with a 5-day intratubular contamination protocol was employed in the present study, this method has been previously demonstrated to be appropriate for evaluating the effectiveness of endodontic treatment against bacteria inside tubules. ${ }^{10,21,24,25,29}$ Moreover, previous biofilm models used to investigate the antimicrobial efficacy of root canal irrigation solutions have employed a similar aspect of biofilm maturity., ${ }^{40-32}$ In general, differences in biofilm biomass/thickness, cell count, and antimicrobial resistance can be observed when comparing limited-maturity biofilms (several hours to days) versus "old" biofilms. Similarly, multispecies biofilms show greater resistance to antimicrobial treatments than single-species biofilms. ${ }^{6}$ Nonetheless, in most endodontic studies involving microbial contamination, biofilms have been performed with axenic models. ${ }^{6}$ Thus, a single-species biofilm model remains a valuable tool for preliminary analysis of the effect of root canal disinfection procedures.

Our findings reveal that bacterial reduction was achieved immediately after the use of instrumentation for a canal, regardless of the irrigation solution used, as shown by the CFU/mL count results and in agreement with previous studies. ${ }^{27,33}$ The immediate effects also effected the samples collected after the use of the adjunctive steps, i.e., PUI and XP-Endo Finisher, which resulted in statistical similarity between the second and third collections. The likely reason for the similarity in these results is that the bacterial samples were collected only from the main root canal using absorbent paper points that are only capable of collecting bacteria in this area and have difficulty in accessing irregular areas and other regions of the root canal system, such as the dentinal tubules. ${ }^{28,34} \mathrm{In}$ addition, some $E$. faecalis cells can enter a stationary phase, rendering them undetectable with conventional culture methods. ${ }^{28,29}$ Another important factor is that the adjunctive steps involve physical-mechanical action on intratubular biofilms; hence, bacteria can be detached from the polysaccharide matrix and start to assume the planktonic form closer to the main canals. Therefore, the obtained $\mathrm{CFU} / \mathrm{mL}$ count data from the main root canal should be interpreted with caution.

NiTi rotary instruments promote a circular preparation, leaving the buccal and lingual extensions of canals with debris. ${ }^{10}$ Thus, mandibular human incisors were chosen for this study due to their flatter conformation, and the same instrumentation technique was performed in the root canals of all experimental groups to obtain comparable specimens. Another important aspect is with regard to the diameter and number of dentinal tubules per $\mathrm{mm}^{2}$ in human permanent dentine, which vary considerably. ${ }^{35}$ In this study, recently extracted human teeth were taken from individuals in a specific age group and radiographed in different directions to standardize the specimens. For this purpose, CLSM is a method that allows detailed visualization; in fact, it has recently been used to show bacteria inside dentinal tubules and can determine the status of bacterial cells..$^{20,24,25}$ With CLSM, optical sections of the dentine mass can be imaged at various depths up to $200 \mu \mathrm{m}$ that are stacked to produce a three-dimensional reconstructed image, ${ }^{6,29}$ representing a large dentine mass when considering mandibular incisors.

In the present work, EDTA was applied for a short time (3 min) for removal of the smear layer only; EDTA was also used after cutting the specimens. Therefore, contamination of the specimens was higher and deeper than that in the tests that confirmed the antimicrobial capacity of EDTA. Intratubular studies have been performed to verify the influence of such superficial EDTA application, and no influence of this weak acid on bacterial viability was observed..$^{21}$ Notably, this procedure was performed for all groups, thus 
enabling comparisons, including bacterial growth in the control group in which higher bacterial viability was evident. ${ }^{10,24,25}$ In addition, the positive control group showed that the 5-day period of intratubular contamination was sufficient to contaminate the entire thickness of the roots from the main canal to the cementum, with biofilm formation by viable bacteria. ${ }^{29}$

In our CLSM analysis, all experimental groups showed a reduced number of viable bacteria in the infected dentin. The groups in which the XP-Endo Finisher instrument was employed exhibited lower viability percentages that were not statistically significant compared to those in the PUI-activated groups. An exception is G6 $(\mathrm{NaOCl}+$ EDTA-T), which presented the lowest viability percentage among the groups in terms of total, superficial, and deep viability $(\mathrm{p}<0.05)$. Additionally, among the PUI-activated groups, a lower percentage (not significant) of bacterial viability was observed in G3 (NaOCl +EDTA-T) (Table 2), which confirms the effect of the surfactant activity of sodium lauryl ether sulfate. Based on the significant difference between G6 and the PUI-activated groups, the null hypothesis tested was rejected. Furthermore, the present results agree with those of other studies adopting different methods to evaluate the antimicrobial action of irrigants combined with surfactants, including chelating agents. ${ }^{24,36,37}$

The disinfection effects of PUI are related to cavitation, acoustic flow and the shockwave phenomenon, generating increased pressure and heating of the solution in the root canal. ${ }^{9}$ De-Deus and coauthors concluded that the XP-Endo Finisher instrument and PUI have the same effectiveness in the removal of accumulated hard-tissue debris from oval-shaped canals. ${ }^{38}$ Nevertheless, Pacheco-Yanes and coauthors found that the XP-Endo Finisher instrument had better performance in distributing irrigant throughout the root canal system. ${ }^{8}$ Thus, we hypothesize that the XP-Endo Finisher has better mechanical agitation effectiveness. Previous studies have reported biofilm reduction in difficult-to-reach areas in the root canal system and main canal space after an adjunctive step with XP-Endo Finisher and $\mathrm{NaOCl}$ solutions, ${ }^{17,39}$ and the design and helical movement of XP-Endo Finisher in the WL may allow it to reach previously untouched areas. As the instrument expands and contracts in the canal, the solution is significantly agitated, and air bubbles are displaced and escape, allowing the solution to better fill the canal ${ }^{8}$ and causing displacement of bacterial biofilms. Overall, the effect which might contribute to the fact that the XP-Endo Finisher groups displayed similar patterns, regardless of the irrigation solution used.

The lower viability results in the XP-Endo Finisher groups may also be related to the phase transformation of this instrument when it contacts saline solution at the intracanal temperature. In this study, heated solutions were used at the experimental agitation phase due to the characteristics of the NiTi alloys in the instrument. Previous studies were performed at room temperature. ${ }^{12,16,17,39}$ Furthermore, because temperature affects the antibacterial activity of $\mathrm{NaOCl}$, it is advisable to perform antibacterial tests at temperatures that are similar to body temperature. ${ }^{12,16}$

The sodium lauryl ether sulfate used in EDTA-T is an anionic surfactant with a protein-denaturing property that is commonly used as an emulsifying cleaning agent in potent inhibition of several viruses. ${ }^{3}$ In addition to enhancement of wetting and spreading abilities, addition of surfactant might improve the bactericidal effectiveness of EDTA. ${ }^{3}$ Analyses of microbiological cultures ${ }^{37}$, viability staining, and CLSM found that irrigation solutions with surfactants had higher antibacterial activity than those without surfactants. ${ }^{24,33}$

The single $\mathrm{NaOCl} / \mathrm{HEBP}$ mixture exhibited effective antibacterial activity. In a recent randomized double-blind trial, no influence of HEBP on clinical $\mathrm{NaOCl}$ effects was found. ${ }^{40}$ The action of $\mathrm{NaOCl}$ solutions is also related to the free chlorine content, which remains stable over time when mixed with HEBP, ${ }^{4}$ therefore, this antimicrobial/weak chelating agent can be used in instrumentation for the root canal or as a final irrigant. ${ }^{2}$ However, EDTA was found to be responsible for the loss of the tissue dissolution capacity of $\mathrm{NaOCl}$ due to the reduction of free chlorine in a unique mixture solution. In addition, EDTA retains its chelating capacity when mixed with $\mathrm{NaOCl}{ }^{41}$ Wright and coauthors found that a mixture of $\mathrm{NaOCl}$ and tetrasodium EDTA $\left(\mathrm{Na}_{4}\right.$ EDTA) is not useful for continuous chelation due to the influence 
of the intracanal temperature on chemical reaction kinetics. ${ }^{42}$ Clinically, these findings suggest that these solutions should be used separately, which justifies the use of EDTA and EDTA-T solutions after irrigation with $\mathrm{NaOCl}$ in the present study.

Another relevant topic is irrigation flow rate. According to recent findings, the irrigation flow rate positively interferes with the removal of artificial biofilms in simulated root canals and is considered a direct factor that affects biofilm removal more than the $\mathrm{NaOCl}$ concentration. ${ }^{20}$ In this previous study, the irrigant velocity in the isthmus and lateral canal increased with increasing flow rate and correlated substantially with biofilm removal from those areas. ${ }^{20}$ In the present study, the flow rate during chemomechanical preparation and adjunctive steps was similar to the highest flow previously investigated $(0.167 \mathrm{~mL} / \mathrm{s})$, considering that irrigation was analyzed in two phases, as also in a previous study. ${ }^{20}$ In the first phase, the $\mathrm{NaOCl}$ solution was used; an inert solution was applied during the second phase. Moreover, in our study, irrigation was performed using needles moved along the root canal by inward and outward movements of $5 \mathrm{~mm}$ amplitude. This factor added to the agitation occurring in the final irrigation can favor reflux as well as better contact by the irrigant.

One may argue that groups subjected to antimicrobial irrigation solutions during adjunctive steps should have been used in the present study. However, the aim of this study was clearly a comparison of the antimicrobial effectiveness of different irrigation solutions and the possibility of achieving greater root canal system disinfection when adjunctive steps are performed with ultrasound or mechanical agitation (PUI or XP-Endo Finisher), considering the indeterminate results in the literature. Additionally, if antimicrobial agents had been used in this step, few or no bacteria would likely have been present, complicating comparison of the devices, which is why agitation was tested with saline solution only.

\section{Conclusion}

All experimental groups showed bacterial reduction, and all groups displayed similar bacterial reductions in terms of $\mathrm{CFU} / \mathrm{mL}$ counts inside the main root canal after chemomechanical preparation and adjunctive steps. According to microscopy images, complete eradication of live bacteria from the dentinal tubules did not occur; however, irrigation with $\mathrm{NaOCl}+$ EDTA-T followed by agitation with the $\mathrm{XP}$-Endo Finisher instrument was superior in this regard. Further studies are warranted to determine better strategies to improve the antimicrobial effects of irrigation procedures, such as investigations of different irrigation times and volumes and combinations of adjunctive steps with different irrigation solutions throughout the root canal system.

\section{Acknowledgments}

The authors thank CAPES (Coordination of Higher Education and Post-Graduation), CNPq (National Council of Scientific and Technological Development), the Pro-Rector of Research and Post-Graduation (Propesp - UFPA), and Fapesp (grant 2010/20186-3) for supporting this study.

\section{References}

1. Siqueira Jr JF, Pérez AR, Marceliano-Alves MF, Provenzano JC, Silva SG, Pires FR et al. What happens to unprepared root canal walls: a correlative analysis using micro-computed tomography and histology/scanning electron microscopy. Int Endod J. 2018 May;51(5):501-8 https://doi.org/10.1111/iej.12753

2. Zehnder M, Schmidlin P, Sener B, Waltimo T. Chelation in root canal therapy reconsidered. J Endod. 2005 Nov;31(11):817-20. https://doi.org/10.1097/01.don.0000158233.59316.fe

3. Güzel C, Uzunoglu E, Buzoglu HD. Effect of low-surface tension EDTA solutions on the bond strength of resin-based sealer to young and old root canal dentin. J Endod. 2018 Mar;44(3):485-8. https://doi.org/10.1016/i.joen.2017.09.007

4. Moliz MTA, Zapata RO, Baca P, Ruiz-Linares M, García EG, Duarte MAH et al. Antimicrobial activity of chlorhexidine, peracetic acid and sodium hypochlorite/etidronate irrigant solutions against Enterococcus faecalis biofilms. Int Endod J. 2015 Dec;48(12):1188-93. https://doi.org/10.1111/iej.12424 
5. Domínguez MCL, Pedrinha VF, Silva LCOA, Ribeiro MES, Loretto SC, Rodrigues PA. Effects of different irrigation solutions on root fracture resistance: an in vitro study. Iran Endod J. 2018 Summer;13(3):367-72. https://doi.org/10.22037/iej.v13i3.19247

6. Swimberghe RCD, Coenye T, De Moor RJG, Meire MA. Biofilm model systems for root canal disinfection: a literature review. Int Endod J. 2019 May; 52(5):604-28. https://doi.org/10.1111/iej.13050

7. Jacinto RC, Gomes BP, Shah HN, Ferraz CC, Zaia AA, Souza Filho FJ. Quantification of endotoxins in necrotic root canals from symptomatic and asymptomatic teeth. J Med Microbiol. 2005 Aug;54(Pt 8):777-83. https://doi.org/10.1099//mm.0.45976-0

8. Pacheco-Yanes J, Provenzano JC, Marceliano-Alves MF, Gazzaneo I, Pérez AR, Gonçalves LS et al. Distribution of sodium hypochlorite throughout the mesial root canal system of mandibular molars after adjunctive irrigant activation procedures: a micro-computed tomographic study. Clin Oral Investig. 2020 Feb;24(2):907-14. https://doi.org/10.1007/s00784-019-02970-5

9. Sluis LW, Versluis M, Wu MK, Wesselink PR. Passive ultrasonic irrigation of the root canal: a review of the literature. Int Endod J. 2007 Jun;40(6):415-26. https://doi.org/10.1111/j.1365-2591.2007.01243.x

10. Vasconcelos LRSM, Midena RZ, Minotti PG, Pereira TC, Duarte MAH, Andrade FB. Effect of ultrasound streaming on the disinfection of flattened root canals prepared by rotary and reciprocating systems. J Appl Oral Sci. 2017 Sep-Oct;25(5):477-82. https://doi.org/10.1590/1678-7757-2016-0358

11. Adcock JM, Sidow SJ, Looney SW, Liu Y, McNally K, Lindsey K et al. Histologic evaluation of canal and isthmus debridement efficacies of two different irrigant delivery techniques in a closed system. J Endod. 2011 Apr;37(4):544-8. https://doi.org/10.1016/i.joen.2011.01.006

12. Alves FRF, Andrade-Junior CV, Marceliano-Alves MF, Perez AR, Rocas IN, Versiani MA et al. Adjunctive steps for disinfection of the mandibular molar root canal system: a correlative bacteriologic, microcomputed tomography, and cryopulverization approach. J Endod. 2016 Nov;42(11):1667-72. https://doi.org/10.1016/i.joen.2016.08.003

13. Spoleti P, Siragusa M, Spoleti MJ. Bacteriological evaluation of passive ultrasonic activation. J Endod. 2003 Jan;29(1):12-4. https://doi.org/10.1097/00004770-200301000-00004

14. Paiva SS, Siqueira Jr JF, Rôças IN, Carmo FL, Leite DC, Ferreira DC et al. Molecular microbiological evaluation of passive ultrasonic activation as a supplementary disinfecting step: a clinical study. J Endod. 2013 Feb;39(2):190-4. https://doi.org/10.1016/i.joen.2012.09.014

15. Leoni GB, Versiani MA, Silva-Sousa YT, Bruniera JF, Pecora JD, Sousa-Neto MD. Ex vivo evaluation of four final irrigation protocols on the removal of hard-tissue debris from the mesial root canal system of mandibular first molars. Int Endod J. 2017 Apr;50(4):398-406. https://doi.org/10.1111/iej.12630

16. Alves FRF, Marceliano-Alves MF, Sousa JCN, Silveira SB, Provenzano JC, Siqueira Jr JF. Removal of root canal fillings in curved canals using either reciprocating single- or rotary multi-instrument systems and a supplementary step with the XP-Endo Finisher. J Endod. 2016 Jul;42(7):1114-9. https://doi.org/10.1016/i.joen.2016.04.007

17. Bao P, Shen Y, Lin J, Haapasalo M. In vitro efficacy of XP-endo finisher with 2 different protocols on biofilm removal from apical root canals. J Endod. 2017 Feb;43(2):321-5. https://doi.org/10.1016/i.joen.2016.09.021

18. Silva EJNL, Belladonna FG, Zuolo AS, Rodrigues E, Ehrhardt IC, Souza EM et al. Effectiveness of XP-endo finisher and XP-endo finisher $R$ in removing root filling remnants: a micro-CT study. Int Endod J. 2018 Jan;51(1):86-91. https://doi.org/10.1111/iej.12788

19. Wigler R, Dvir R, Weisman A, Matalon S, Kfir A. Efficacy of XP-endo finisher files in the removal of calcium hydroxide paste from artificial standardized grooves in the apical third of oval root canals. Int Endod J. 2017 Jul;50(7):700-5. https://doi.org/10.1111/iej.12668

20. Pereira TC, Boutsioukis C, Dijkstra RJB, Petridis X, Versluis M, Andrade FB et al. Biofilm removal from a simulated isthmus and lateral canal during syringe irrigation at various flow rates: a combined experimental and computational fluid dynamics approach. Int Endod J. 2021 Mar;54(3):427-38. https://doi.org/10.1111/iej.13420

21. Andrade FB, Arias MP, Maliza AG, Duarte MA, Graeff MS, Amoroso-Silva PA et al. A new improved protocol for in vitro intratubular dentinal bacterial contamination for antimicrobial endodontic tests: standardization and validation by confocal laser scanning microscopy. J Appl Oral Sci. 2015 Nov-Dec;23(6):591-8. https://doi.org/10.1590/1678-775720140261

22. Marinho ACS, Martinho FC, Goncalves LM, Rabang HRC, Gomes BPFA. Does the reciproc file remove root canal bacteria and endotoxins as effectively as multifile rotary systems? Int Endod J. 2015 Jun;48(6):542-8. https://doi.org/10.1111/iej.12346

23. Ma J, Wang Z, Shen Y, Haapasalo M. A new noninvasive model to study the effectiveness of dentin disinfection by using confocal laser scanning microscopy. J Endod. 2011 Oct;37(10):1380-5. https://doi.org/10.1016/i.joen.2011.06.018

24. Giardino L, Del Fabbro M, Cesario F, Fernandes FS, Andrade FB. Antimicrobial effectivenesss of combinations of oxidant and chelating agents in infected dentine: an ex vivo confocal laser scanning microscopy study. Int Endod J. 2018 Apr;51(4):448-56. https://doi.org/10.1111/iej.12863

25. Pereira TC, Vasconcelos LRSM, Graeff MSZ, Ribeiro MCM, Duarte MAH, Andrade FB. Intratubular decontamination ability and physicochemical properties of calcium hydroxide pastes. Clin Oral Investig. 2019 Mar;23(3):1253-62. https://doi.org/10.1007/s00784-018-2549-0

26. Cuellar MRC, Velásquez-Espedilla EG, Pedrinha VF, Vivan RR, Duarte MAH, Andrade FB. Can kinematics, file diameter, and PUI influence the intracanal decontamination and apical bacterial extrusion? Braz Oral Res. 2020;35:e003. https://doi.org/10.1590/1807-3107bor-2021.vol35.0003 
Impact of irrigation protocols with some chelators and mechanical agitation on intratubular decontamination

27. Ferrer-Luque CM, Bejarano I, Ruiz-Linares M, Baca P. Reduction in Enteroccocus faecalis counts: a comparison between rotary and reciprocating systems. Int Endod J. 2014 Apr;47(4):380-6. https://doi.org/10.1111/iej.12158

28. Ohsumi T, Takenaka S, Wakamatsu R, Sakaue Y, Narisawa N, Senpuku H et al. Residual structure of Streptococcus mutans biofilm following complete disinfection favors secondary bacterial adhesion and biofilm re-development. PLoS One. 2015 Jan 30;10(1):e0116647. https://doi.org/10.1371/journal.pone.0116647

29. Pereira TC, Dijkstra RJB, Petridis X, Sharma PK, Meer WJ, Sluis LWM et al. Chemical and mechanical influence of root canal irrigation on biofilm removal from lateral morphological features of simulated root canals, dentine discs and dentinal tubules. Int Endod J. 2021 Jan;54(1):112-29. https://doi.org/10.1111/iej.13399

30. Liu H, Wei X, Ling J, Wang W, Huang X. Biofilm formation capability of Enterococcus faecalis cells in starvation phase and its susceptibility to sodium hypochlorite. J Endod. 2010 Apr;36(4):630-5. https://doi.org/10.1016/i.joen.2009.11.016

31. Rossi-Fedele G, Figueiredo JA, Steier L, Canullo L, Steier G, Roberts AP. Evaluation of the antimicrobial effect of super-oxidized water (Sterilox $\AA_{\text {) }}$ and sodium hypochlorite against Enterococcus faecalis in a bovine root canal model. J Appl Oral Sci. 2010;18(5):498-502. https://doi.org/10.1590/S1678-77572010000500012

32. Guerreiro JCM, Ochoa-Rodrígez VM, Rodrigues EM, Chavez-Andrade GM, Tanomaru-Filho M, Guerreiro-Tanomaru JM et al. Antibacterial activity, cytocompatibility and effect of Bio-C Temp bioceramic intracanal medicament on osteoblast biology. Int Endod J. 2021 Feb 27. https://doi.org/10.1111/iej.13502

33. Nakamura VC, Cai S, Candeiro GTM, Ferrari PH, Caldeira CL, Gavini G. Ex vivo evaluation of the effects of several root canal preparation techniques and irrigation regimens on a mixed microbial infection. Int Endod J. 2013 Mar;46(3):217-24. https://doi.org/10.1111/j.1365-2591.2012.02110.x

34. Siqueira JF Jr, Alves FR, Almeida BM, Oliveira JC, Rôças IN. Ability of chemomechanical preparation with either rotary instruments or self-adjusting file to disinfect oval-shaped root canals. J Endod. 2010 Nov;36(11):1860-5. https://doi.org/10.1016/i.joen.2010.08.001

35. Schilke R, Lisson JA, Bauss $O$, Geurtsen W. Comparison of the number and diameter of dentinal tubules in human and bovine dentine by scanning electron microscopic investigation. Arch Oral Biol. 2000 May;45(5):355-61. https://doi.org/10.1016/s0003-9969(00)00006-6

36. Wang Z, Shen Y, Ma J, Haapasalo M. The effect of detergents on the antibacterial activity of disinfecting solutions in dentin. J Endod. 2012 Jul;38(7):948-53. https://doi.org/10.1016/i.joen.2012.03.007

37. Bolfoni MC, Santos FM, Silva SO, Giardino L, Castilho JR, Pappen GF. The effect of a surfactant in the antimicrobial activity of sodium hypochlorite solutions. Braz Dent J. 2014 Sep-Oct;25(5):416-9. https://doi.org/10.1590/0103-6440201300049

38. De-Deus G, Belladonna FG, Zuolo AS, Perez R, Carvalho MS, Souza EM et al. Micro-CT comparison of XP-endo finisher and passive ultrasonic irrigation as final irrigation protocols on the removal of accumulated hard-tissue debris from oval shaped-canals. Clin Oral Investig. 2019 Jul;23(7):3087-93. https://doi.org/10.1007/s00784-018-2729-y

39. Azim AA, Aksel H, Zhuang T, Mashtare T, Babu JP, Huang GT. Efficacy of 4 irrigation protocols in killing bacteria colonized in dentinal tubules examined by a novel confocal laser scanning microscope analysis. J Endod. 2016 Jun;42(6):928-34. https://doi.org/10.1016/i.joen.2016.03.009

40. Ballal NV, Gandhi P, Shenoy PA, Shenoy Belle V, Bhat V, Rechenberg D. Safety assessment of an etidronate in a sodium hypochlorite solution: randomized double-blind trial. Int Endod J. 2019 Sep;52(9):1274-82. https://doi.org/10.1111/iej.13129

41. Grawehr M, Sener B, Waltimo T, Zehnder M. Interactions of ethylenediamine tetraacetic acid with sodium hypochlorite in aqueous solutions. Int Endod J. 2003 Jun;36(6):411-7. https://doi.org/10.1046/i.1365-2591.2003.00670.x

42. Wright PP, Kahler B, Walsh LJ. The effect of heating to intracanal temperature on the stability of sodium hypochlorite admixed with etidronate or EDTA for continuous chelation. J Endod. 2019 Jan;45(1):57-61. https://doi.org/10.1016/j.joen.2018.09.014 